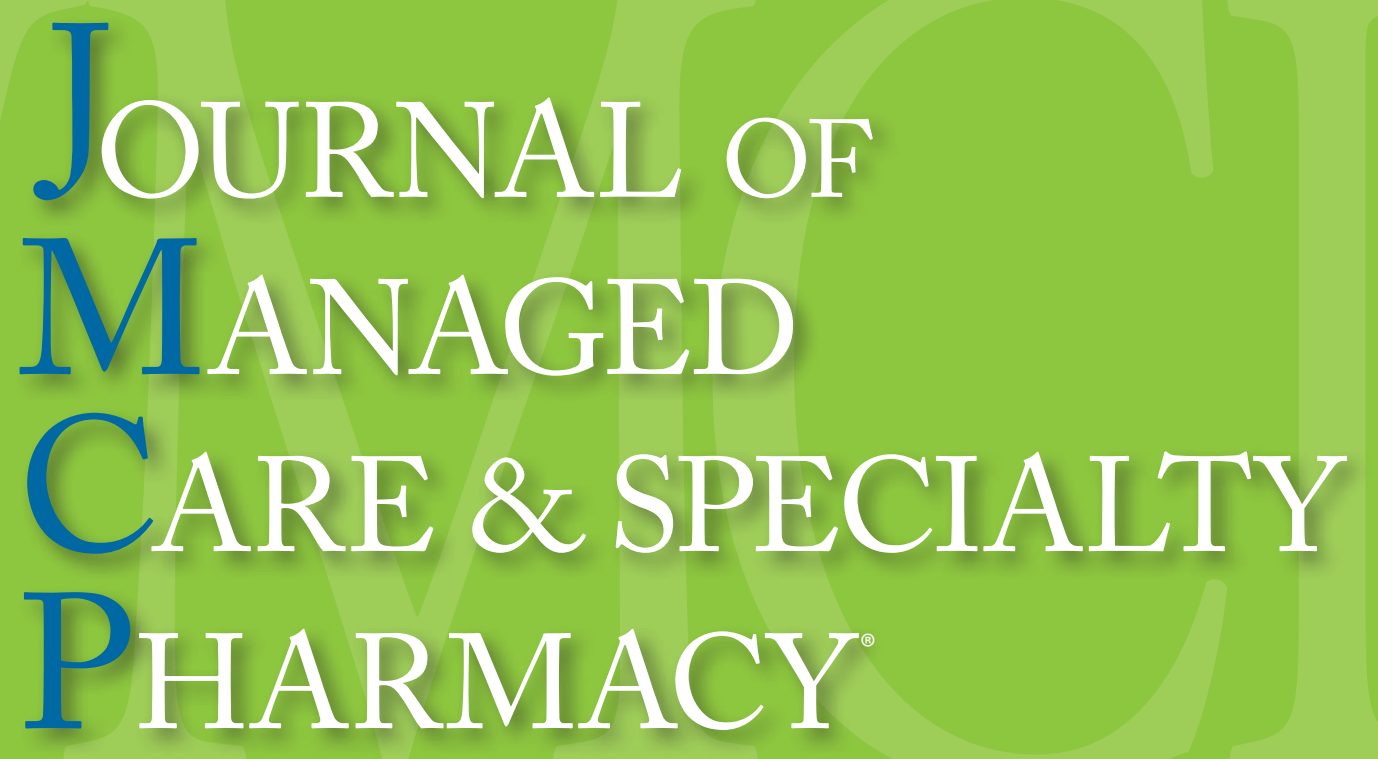

Supplement $\square$ Volume 24 口 Number 12-a 口 December 2018

\title{
Gene Therapy for Spinal Muscular Atrophy: An Emerging Treatment Option for a Devastating Disease
}

Vamshi K. Rao, MBBS, MD; Daniel Kapp, PharmD, BCPS; and Mary Schroth, MD 


\section{/MCP}

\section{Publisher}

Susan A. Cantrell, RPh, CAE

Chief Executive Officer

Academy of Managed Care Pharmacy

\section{Editor-in-Chief}

Laura E. Happe, PharmD, MPH

727.488.2700, lhappe@jmcp.org

\section{Assistant Editors}

Donald G. Klepser, PhD, MBA

University of Nebraska Medical Center, Omaha, NE

Melissa S. McCart, PharmD, MS

Xcenda, Palm Harbor, FL

Robert P. Navarro, PharmD

University of Florida College of Pharmacy, Gainesville, FL

Karen L. Rascati, PhD

University of Texas College of Pharmacy, Austin, TX

\section{Managing Editor}

Jennifer A. Booker

703.317.0725, jmcpreview@amcp.org

\section{Production Editor}

Carol Blumentritt

602.616.7249, cblumentritt@amcp.org

\section{Graphic Designer}

Margie C. Hunter

703.297.9319,mhunter@amcp.org

\section{Account Manager}

Bryan Bonder

American Medical Communications

610.715.4384,Bbonder@americanmedicalcomm.com

Maria Sercia

American Medical Communications

908.216.1548,MSercia@americanmedicalcomm.com

This supplement to the Journal of Managed Care \& Specialty Pharmacy (ISSN 1944-706X) is a publication of the Academy of Managed Care Pharmacy, 675 North Washington Street, Suite 220, Alexandria, VA 22314; 703.684.2600; 703.684 .2651 (fax).

Copyright $\odot$ 2018, Academy of Managed Care Pharmacy. All rights reserved. No part of this publication may be reproduced or transmitted in any form or by any means, electronic or mechanical, without written permission from the Academy of Managed Care Pharmacy. POSTMASTER: Send address changes to JMCP,

675 North Washington Street, Suite 220, Alexandria, VA 22314.

\section{Supplement Policy Statement} Standards for Supplements to the Journal of Managed Care \& Specialty Pharmacy Supplements to the Journal of Managed Care E Specialty Pharmacy (JMCP) are intended to support medical education and research in areas of clinical practice, health care quality improvement, or efficient administration and delivery of health benefits. The following standards are applied to all JMCP supplements to ensure quality and assist readers in evaluating potential bias and determining alternate explanations for findings and results.

1. Disclose the principal sources of funding in a manner that permits easy recognition by the reader.

2 . Disclose the existence of all potential conflicts of interest among supplement contributors, including financial or personal bias.

3. Describe all drugs by generic name unless the use of the brand name is necessary to reduce the opportunity for confusion among readers.

4. Identify any off-label (unapproved) use by drug name and specific off-label indication.

5. Strive to report subjects of current interest to managed care pharmacists and other managed care professionals.

6. Seek and publish content that does not duplicate content in the Journal of Managed Care \& Specialty Pharmacy.

7. Subject all supplements to expert peer review.

\section{AUTHORS}

Vamshi K. Rao, MBBS, MD, is a pediatric neurologist and Attending Neuromuscular Physician at Lurie Children's Hospital in Chicago, where he is involved in the Muscular Dystrophy Association and Parent Project Muscular Dystrophy certified neuromuscular clinic. The clinic oversees care of more than 500 children with neuromuscular disorders. He holds the Assistant Professor appointment in the Department of Pediatrics at the Northwestern University Feinberg School of Medicine. He completed his pediatrics training at the John H. Stroger Jr. Hospital of Cook County, and his child neurology and neuromuscular medicine fellowship at the McGaw Medical Center of Northwestern University and Lurie Children's Hospital in Chicago. He has a masters of science degree in biomedical engineering from the University of Tennessee Health Science Center in Memphis, where his work involved muscle proteomics. Rao currently participates in several collaborative pediatric neuromuscular trials as primary or subinvestigator in addition to studying natural history and pathophysiologic mechanisms underlying rare disorders.

Daniel Kapp, PharmD, BCPS, is a clinical pharmacist in the Drug Policy Program and is the PGY-2 Drug Information Residency Coordinator at University of Wisconsin Health in Madison. He received his bachelor of science in pharmacology and toxicology, and his doctor of pharmacy degree from the University of Wisconsin-Madison, completed a PGY-1 Pharmacy Practice residency at Marshfield Clinic in Marshfield, Wisconsin, and completed his PGY-2 Drug Information specialty residency at Froedtert $\&$ the Medical College of Wisconsin in Milwaukee. His practice areas include breakthrough therapy evaluation, oncology formulary management, medication value optimization, clinical practice guideline development, and smart infusion pump library management.

Mary Schroth, MD, is the Chief Medical Officer for Cure SMA, a national nonprofit dedicated to the treatment and cure of spinal muscular atrophy (SMA). She is also a pediatric pulmonologist and Professor Emerita at the University of Wisconsin School of Medicine and Public Health. She has educated, lectured, and written about SMA throughout her career. She received her medical degree from University of Wisconsin School of Medicine and Public Health.

\section{ACCREDITATION STATEMENTS}

The France Foundation is accredited by the Accreditation Council for Continuing Medical Education (ACCME) to provide continuing medical education for physicians.

\section{Physicians}

The France Foundation designates this enduring activity for a maximum of 2.0 AMA PRA Category 1 Credits. Physicians should claim only the ACCME ACREDITED credit commensurate with the extent of their participation in the activity.

\section{Pharmacists}

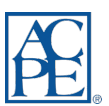

The France Foundation is accredited by the Accreditation Council for Pharmacy Education as a provider of continuing pharmacy education and will award 2.0 CEU to pharmacists who complete the activity, complete the registration and evaluation forms, and successfully pass a posttest $(>70 \%)$. There is no fee to participate in this activity. This is a knowledge educational activity. Your CE credits will be submitted electronically to the CPE Monitor. CE providers must upload participant information within 60 days from the date the participant completed the activity. Please submit all evaluations and credit requests no later than 30 days after you complete this activity to ensure your credit fulfillment, as CE credit cannot be awarded past 60 days from the activity date. ACPE No. 0391-0000-18-096-H01-P.

\section{Nurses}

$\Longleftrightarrow$ ANCC Nurses who are certified by the American Nurses Credentialing Center (ANCC) may utilize activities that are certified by ACCME-accredited providers toward their requirement for certification renewal by the ANCC. A certificate of attendance will be provided by The France Foundation, an ACCME-accredited provider. 


\section{Table of Contents}

Gene Therapy for Spinal Muscular Atrophy: An Emerging Treatment Option for a Devastating Disease

Vamshi K. Rao, MBBS, MD; Daniel Kapp, PharmD, BCPS; and Mary Schroth, MD

\section{S3 Abstract}

S3 What Is SMA?

S4 Genetics and Diagnosis of SMA

S4 Current and Emerging SMA Treatments

S10 Anticipating Availability of Gene Therapy for SMA: How Do Hospitals and Health Care Systems Need to Prepare?

\section{S12 Summary \\ S13 References \\ S16 Posttest}

\section{Learning Objectives}

- Demonstrate knowledge of spinal muscular atrophy (SMA) and its contemporary treatment

- Explain genetic aspects of SMA, including its recessive nature, carriers, and recommendations for genetic screening

- Explore potential implications for gene therapy in SMA

- Summarize key clinical trial data on gene therapy for SMA

Plan approaches to formulary management to ensure timely access to newly approved therapies

Target Audience

This activity is intended for medical directors and other health care professionals in managed care.

Funding

This activity is provided by an educational grant from AveXis, managed by The France Foundation.

The release date is December 31, 2018. 


\section{CREDIT INSTRUCTIONS}

1. There are no fees for participating in and receiving credit for this activity.

2. Review the activity objectives and CME/CE information.

3. Complete the $\mathrm{CME} / \mathrm{CE}$ activity.

4. Complete the online posttest and CME/CE evaluation/attestation form. To complete, direct your web browser to: https://www.surveygizmo.com/s3/4751258/9814-SMA-Managed-Care-Supplement. A score of at least $75 \%$ on the posttest is required to successfully complete this activity. The participant may take the test until successfully passed.

5. Credit documentation/reporting:

- If you are requesting AMA PRA Category 1 Credits or a certificate of participation-your CME/CE certificate will be available for download.

- If you are requesting ACPE pharmacy credit, your CE credits will be submitted electronically to the CPE Monitor.

\section{DISCLOSURES}

In accordance with the ACCME Standards for Commercial Support, The France Foundation (TFF) requires that individuals in a position to control the content of an educational activity disclose all relevant financial relationships with any commercial interest. TFF resolves all conflicts of interest to ensure independence, objectivity, balance, and scientific rigor in all its educational programs. Furthermore, TFF seeks to verify that all scientific research referred to, reported, or used in a CME/CE activity conforms to the generally accepted standards of experimental design, data collection, and analysis. TFF is committed to providing learners with high-quality CME/CE activities that promote improvements in health care and not those of a commercial interest.

- Activity Staff Disclosures

o The planners, reviewers, editors, staff, CME committee, or other members at The France Foundation who control content have no relevant financial relationships to disclose.

\section{- Faculty Disclosures}

The following faculty report that they have relevant financial relationships to disclose:

o Mary K. Schroth, MD, reports that she served on an Advisory Board for AveXis, served on Data and Safety Monitoring Board for Biogen and Ionis and is employed by Cure SMA.

o Vamshi K. Rao, MBBS, MD, reports that he served on an Advisory Board for AveXis.

The following faculty report that they have no financial relationships to disclose:

o Daniel Kapp, PharmD, BCPS

- Disclosure of Unlabeled Use

TFF requires CME faculty (speakers) to disclose when products or procedures being discussed are off label, unlabeled, experimental, and/ or investigational, and any limitations on the information that is presented, such as data that are preliminary, or that represent ongoing research, interim analyses, and/or unsupported opinion. Faculty in this activity may discuss information about pharmaceutical agents that is outside of U.S. Food and Drug Administration-approved labeling. This information is intended solely for continuing medical education and is not intended to promote off-label use of these medications. TFF does not recommend the use of any agent outside of the labeled indications. If you have questions, contact the Medical Affairs Department of the manufacturer for the most recent prescribing information.

\section{DISCLAIMER}

The France Foundation presents this information for educational purposes only. The content is provided solely by faculty who have been selected because of recognized expertise in their field. Participants have the professional responsibility to ensure that products are prescribed and used appropriately on the basis of their own clinical judgment and accepted standards of care. The France Foundation and the commercial supporter(s) assume no liability for the information herein.

\section{COPYRIGHT INFORMATION}

Copyright $\odot 2018$ The France Foundation. Any unauthorized use of any materials on the site may violate copyright, trademark, and other laws. You may view, copy, and download information or software ("Materials") found on the site subject to the following terms, conditions, and exceptions:

- The materials are to be used solely for personal, noncommercial, informational, and educational purposes. The materials are not to be modified. They are to be distributed in the format provided with the source clearly identified. The copyright information or other proprietary notices may not be removed, changed, or altered.

- Materials may not be published, uploaded, posted, transmitted (other than as set forth herein), without The France Foundation's prior written permission.

\section{PRIVACY POLICY}

The France Foundation protects the privacy of personal and other information regarding participants and educational collaborators. The France Foundation will not release personally identifiable information to a third party without the individual's consent, except such information as is required for reporting purposes to the ACCME.

The France Foundation maintains physical, electronic, and procedural safeguards that comply with federal regulations to protect against the loss, misuse, or alteration of information that we have collected from you.

Additional information regarding The France Foundation's Privacy Policy can be viewed at: http://www.francefoundation.com/privacy.

\section{CONTACT INFORMATION}

If you have questions about this CME activity, please contact The France Foundation at 860.434.1650 or info@francefoundation.com. 


\title{
Gene Therapy for Spinal Muscular Atrophy: An Emerging Treatment Option for a Devastating Disease
}

\author{
Vamshi K. Rao, MBBS, MD; Daniel Kapp, PharmD, BCPS; Mary Schroth, MD
}

\begin{abstract}
BACKGROUND: Spinal muscular atrophy (SMA) is an autosomal recessive neurodegenerative disease that, in most cases, involves homozygous deletion of the SMN1 gene. This causes a deficiency in survival motor neuron (SMN) protein, which plays a critical role in motor neuron development. SMA has a range of phenotype expression resulting in variable age of symptom onset, maximum motor strength achieved, and survival. Without intervention, infants with a more severe form of the disease (type 1 SMA) die before 2 years of age. Although it is rare, SMA is the most common fatal inherited disease of infancy, and until recently, treatment was primarily supportive. In 2016, a new agent, nusinersen, was approved by the FDA. Other treatments are in development, including a gene therapy, AVXS-101. These treatments are not only improving the lives of patients with SMA and their families, they are changing the disease phenotype. They have the greatest benefit when given early in the disease course.

OBJECTIVES: To discuss current knowledge about SMA, provide clinical evidence for available and emerging treatment options, and present approaches for adding new therapies to hospital/health system formularies to ensure timely access to newly approved therapies for SMA.

SUMMARY: Advances in clinical care have significantly extended the lives of individuals with SMA, and research into the genetic mechanisms leading to disease have revealed strategies for intervention that target the underlying cause of SMA. Nusinersen is now on the market, and other treatment options, such as AVXS-101, may soon be approved. This article provides an overview of SMA and the genetic mechanisms leading to SMN deficiency, then describes how new and emerging treatments work to overcome this deficiency and prevent associated nerve damage and disability. In addition, we discuss steps for incorporating AVXS-101 into hospital/health system formularies, along with barriers and concerns that may delay access, based in part on lessons learned with nusinersen.
\end{abstract}

J Manag Care Spec Pharm. 2018;24(12-a):S3-S16

Copyright $\odot 2018$, Academy of Managed Care Pharmacy. All rights reserved.

S pinal muscular atrophy (SMA) is an autosomal recessive neurodegenerative disease that, in most cases, involves deletion of a gene, SMN1, leading to a deficiency in survival motor neuron (SMN) protein. Although rare-occurring in 1 in 11,000 births ${ }^{1}$-it is nevertheless the most common fatal genetic disease of infancy. ${ }^{2}$ Advancements in clinical care, especially technological improvements in pulmonary care and aggressive nutritional support, have significantly extended the lives of individuals with SMA. ${ }^{3}$ Furthermore, a therapy approved by the U.S. Food and Drug Administration (FDA), nusinersen (Spinraza) — a splicing modifier that increases SMN levels-has dramatically altered the natural history of the disease. ${ }^{4}$ Gene therapy (AVXS-101, onasemnogene abeparvovec, Zolgensma) using an adeno-associated virus 9 (AAV9) vector that carries an SMN1 cDNA cargo is also showing great promise and has been submitted for FDA review for possible approval to treat SMA type 1 (SMAl), the most severe form of SMA, for infants and toddlers. ${ }^{5,6}$ Additional treatments now in clinical trials include oral small molecules-a fast-skeletal muscle troponin activator (reldesemtiv [CK-2127107]) and 2 splicing modifiers (branaplam [LMI070] and risdiplam [RG7916]); still others are in preclinical stages of development. ${ }^{7}$ This article provides an overview of SMA, a review of nusinersen clinical trials and how they have improved understanding of SMA treatment, and a discussion of treatments in development, with a particular focus on gene therapy and AVXS-101 clinical trial findings. Also discussed are lessons learned from facilitating availability of nusinersen in hospitals and health care systems postapproval and ways to anticipate and prepare for availability of AVXS-101, should it be approved by the FDA.

\section{What Is SMA?}

SMA is a neurodegenerative disease affecting the motor neurons in the anterior horn of the spinal cord. It is associated with progressive motor weakness. ${ }^{8}$ The course of the disease is distinct from other degenerative motor neuron diseases in that the greatest rate of motor strength and function loss occurs with disease onset, followed by a slower rate of disease progression, eventually leading, in many cases, to early mortality. ${ }^{9}$

Individuals with SMA are classified into 1 of 5 types based on timing of disease onset and maximum motor function achieved, with some variation within types in level of function and clinical course. SMA type 0 is unique from the other types in that symptoms begin in utero. The disease is quite severe, and at birth, these infants typically have joint contractures, respiratory distress, and diffuse hypotonia. They do not survive the neonatal period without intervention. ${ }^{9}$ SMA type 1 (SMAl) is the most common form, affecting about $60 \%$ of those with the disease..$^{10}$ Symptoms include hypotonia, difficulty breathing or feeding, and motor delays that start before 6 months of age. In addition to life-threatening pulmonary complications, individuals with SMAl often have bulbar dysfunction and dysphagia because of muscle weakness. As a result, they may have nutritional compromise and failure to thrive. They may develop progressive motor weakness and fatigue, joint contractures, and scoliosis., ${ }^{3,11,12}$ These patients never sit and have a life expectancy of $<2$ years without intervention. The primary cause of death is pulmonary compromise, because of respiratory muscle weakness leading to severe restrictive lung disease and progressive respiratory failure. ${ }^{13,14}$ In a natural history study of 26 infants age less than 6 months with SMAl recruited from 14 sites within the National Network for Excellence in Neuroscience Clinical Trials, median survival was 8 months. ${ }^{11}$ In a second natural history study of 34 infants with SMAl recruited from 3 clinical trial sites, median survival and/or time to ventilation dependence $\geq 16$ hours was 13.5 months. ${ }^{12}$ 


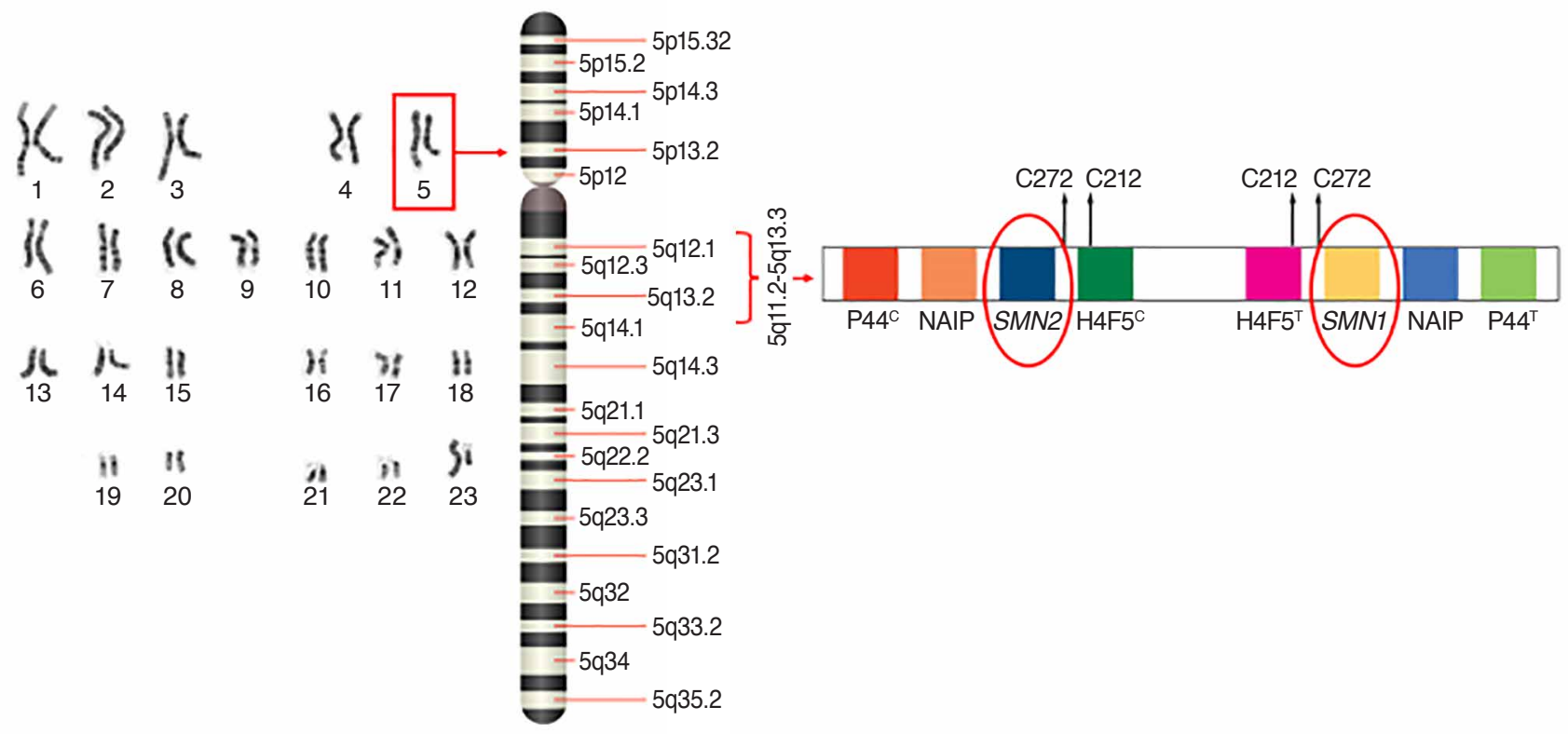

Note: SMN1 and SMN2 genes (circled in red) are found on chromosome 5q, in position 5q11.2-5q13.3.

SMN=survival motor neuron.

In children with SMA type 2 (SMA2), symptoms usually begin later but before age 18 months. These children sit but do not walk and survive into early adulthood. Children with SMA type 3 (SMA3) have comparatively mild symptoms that begin after 18 months. They stand independently and may walk, although they may lose this ability in their teens or later, and they survive well into adulthood. ${ }^{13,14}$ Finally, individuals with SMA type 4 (SMA4) have the mildest form of the disease. Symptoms begin in adulthood and progress very slowly. These patients stand, may walk, and usually have normal lifespans. ${ }^{13,14}$

\section{Genetics and Diagnosis of SMA}

SMA is caused by abnormalities in the SMN1 gene on chromosome 5q (Figure 1). ${ }^{15}$ The SMN1 gene product-SMN protein-is crucial for motor neuron development. In approximately $95 \%$ of patients, SMA results from homozygous deletion or conversion of SMN1. ${ }^{1}$ In about $2 \%$ of patients, de novo deletions occur in one of the SMN1 alleles; in 3\%-4\%, other mutations can be found, typically with an SMN1 deletion on the other allele. ${ }^{16}$ On the same chromosome, a nearly identical gene, SMN2, is often referred to as a "backup" gene for SMN1. It encodes the same protein, but in much lower levels, because most mRNA transcripts exclude exon 7 and are translated to an unstable protein that is rapidly degraded (Figure 2); only a small percentage of messenger RNA transcripts include all exons and are transcribed to full-length, stable SMN protein. Individuals with SMA have at least one copy of SMN2, and variation in the number of SMN2 copies is associated with severity of disease, with more copies associated with milder phenotypes (Table 1) ${ }^{7,11}$

Diagnosis of SMA involves molecular genetic testing for homozygous deletion of SMN1 in patients with symptoms typical of the disease. ${ }^{17}$ In cases where symptoms suggest SMA but 1 copy of SMN1 is present, or genetic testing is negative, full sequencing of SMN1 should be completed to look for other mutations. SMN2 copy number is also obtained when testing for SMN1, and the number of SMN2 copies correlates with severity of phenotype, with fewer copies associated with more severe disease.$^{18}$ For example, patients with SMAl typically have 2 copies of SMN2 and those with SMA2 typically have 3 copies of SMN2 (Table 1). However, there are exceptions, and in individual cases, the number of SMN2 copies may not predict severity of disease and may not account for intrafamilial variation in siblings with SMA. ${ }^{9,20}$

\section{Current and Emerging SMA Treatments}

Until recently, management of SMA has consisted primarily of supportive care to slow or prevent respiratory failure, nutritional compromise, scoliosis, and joint contractures. Respiratory care includes the use of devices that improve ventilation, especially during sleep and viral illnesses when hypoventilation is most 

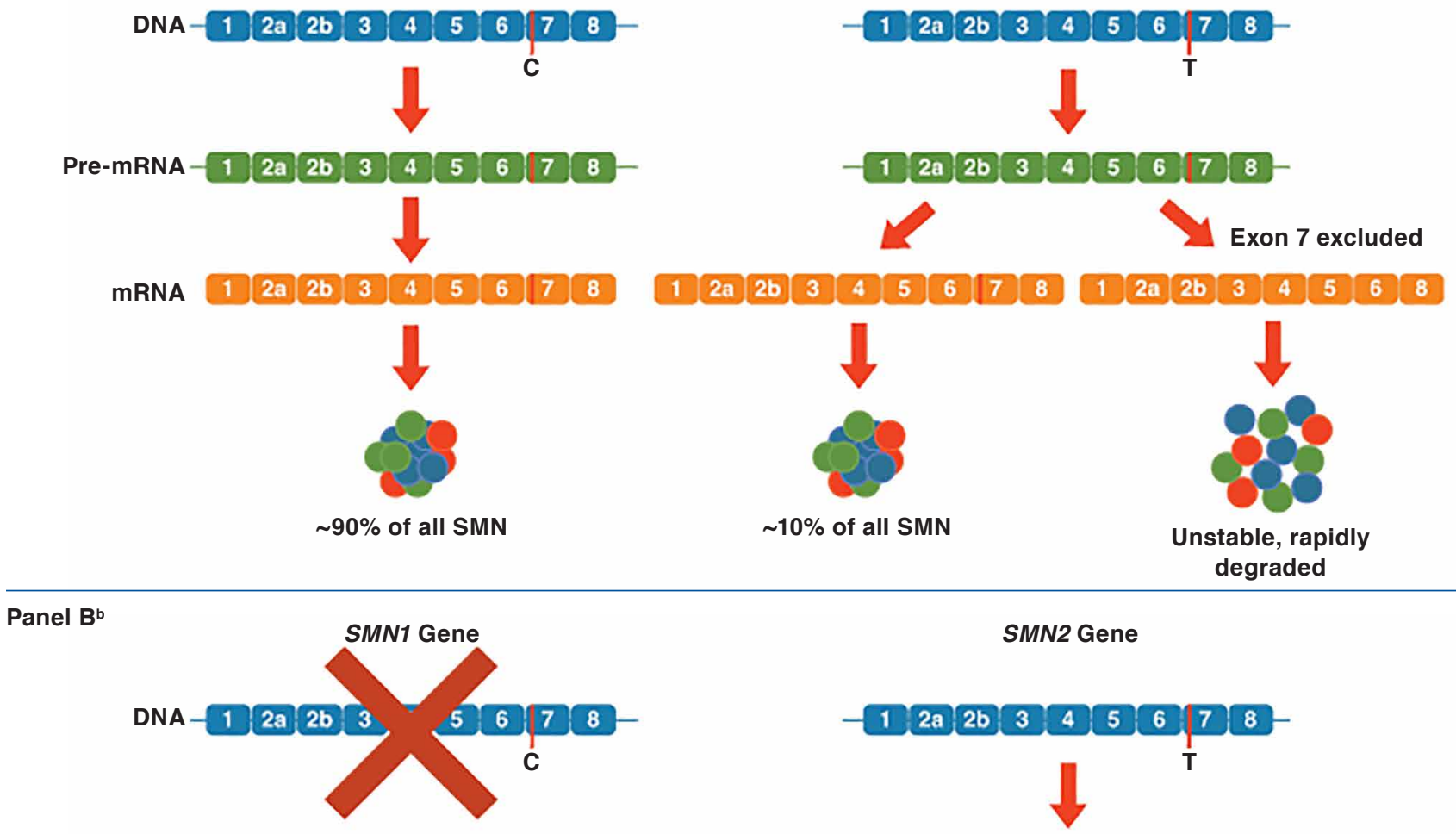

Pre-mRNA
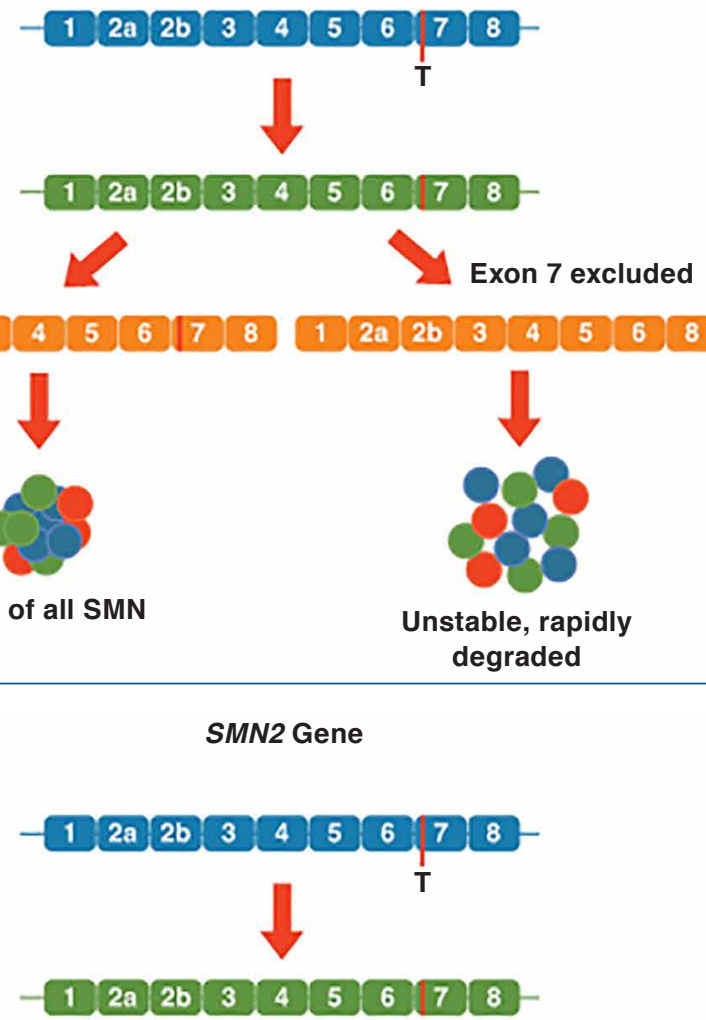

mRNA

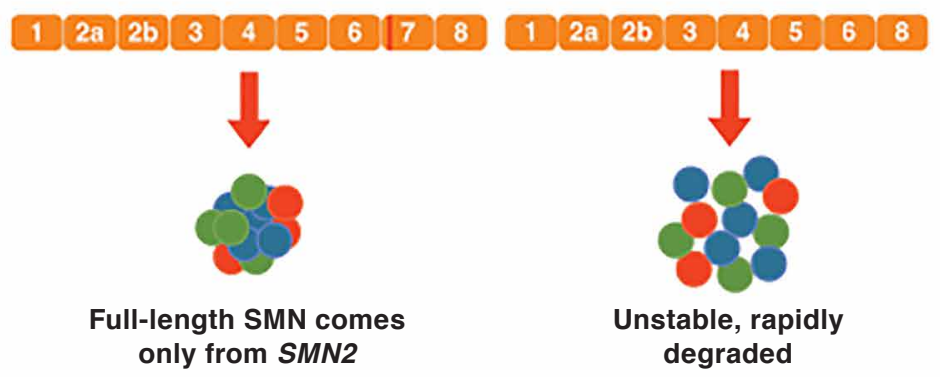

Adapted from: Farrar MA, Park SB, Vucic S, et al. Emerging therapies and challenges in spinal muscular atrophy. ${ }^{7}$

an normal individuals, about 90\% of SMN protein is a product of the SMN1 gene. Translation of a "backup" gene, SMN2, yields a mix of mRNA-most of which lacks exon 7 and yields an unstable protein that is rapidly degraded. Only about 10\% of functional SMN protein comes from the SMN2 gene.

bIn individuals with spinal muscular atrophy, the SMN1 gene is missing or mutated. The SMN2 gene is retained, but because most mRNA transcripts lack exon 7, these individuals have very low levels of SMN protein.

SMN=survival motor neuron.

likely to occur, as well as methods to mechanically augment cough and clearance of respiratory secretions. ${ }^{11}$ Nutritional support includes the use of nonoral methods to deliver enteral nutrition, typically through a surgically placed feeding tube or temporary nasal tube, plus medical or surgical interventions to control gastroesophageal reflux. ${ }^{17,21}$ Management of joint contractures and scoliosis involves aggressive physical therapy assessments, daily passive range of motion exercises, and use 
TABLE 1 Spinal Muscular Atrophy Classification

\begin{tabular}{l|c|c|l|c} 
Type & Age at Onset & Development & Lifespan & $\begin{array}{c}\text { SMN2 Copy } \\
\text { Number }\end{array}$ \\
\hline 0 & Prenatal & Respiratory support & $<1$ month & 1 \\
\hline 1 & $0-6$ months & Never sit & $<2$ years & 2 \\
\hline 2 & $<18$ months & Never stand & $>2$ years & $3-4$ \\
\hline 3 & $>18$ months & Stand unassisted & Adult & $3-4$ \\
\hline 4 & $>21$ years & Stand unassisted & Adult & $4-8$ \\
\hline
\end{tabular}

Adapted from: Iannaccone ST. Modern management of spinal muscular atrophy. ${ }^{13}$ SMN = survival motor neuron

of bracing to facilitate and maintain optimal positioning of extremities and maintain the spine upright against gravity. Surgical intervention with internal fixation of the spine may also be needed. ${ }^{13,17,22}$ Over time, these supportive interventions have prolonged life and slowed the natural history of SMA.,22

\section{Nusinersen}

In December 2016, the FDA approved nusinersen, an antisense oligonucleotide (ASO), for treatment of all SMA types. ASOs are single-stranded nucleic acid sequences designed to target specific regions of pre-mRNA and modulate gene expression. Nusinersen is designed to bind a splicing silencer region on SMN2 pre-mRNA, displacing a splicing repressor protein and boosting transcription of full-length SMN2 mRNA (Figure 3).23,24 This, in turn, boosts translation of full-length, stable, and functional SMN protein. Because ASOs do not efficiently cross the blood-brain barrier, nusinersen is delivered by intrathecal injection..$^{25}$

FDA approval of nusinersen was based on efficacy and safety findings from several clinical trials. Among them was a double-blind, randomized, phase 3 clinical trial involving 121 symptomatic infants with type $1 \mathrm{SMA}<7$ months of age. ${ }^{4}$ At a prespecified interim analysis, performed when 80 infants had been enrolled for $\geq 6$ months, $41 \%$ of those receiving nusinersen showed motor improvements based on scores on the Hammersmith Infant Neurological Exam (HINE). By comparison, no infants who underwent the sham procedure showed improvement, and the difference between study groups was significant $(P<0.001$; see Table 2 for a summary of neurologic function measures used in SMA clinical trials). This finding prompted early termination of the trial, and patients were enrolled in an open-label extension study wherein all would receive nusinersen. ${ }^{4}$ Final analysis of the data showed that nusinersen improved motor milestone achievement in 51\% of treated infants compared with no infants who underwent a sham procedure. Furthermore, the likelihood of event-free survival (defined as time to death or use of permanent assisted ventilation) was also higher in the nusinersen group $(P=0.005){ }^{4}$ A second multicenter, double-blind, randomized, phase 3 trial involving 126 children with later-onset SMA (symptom onset
$>6$ months of age) revealed significant improvement on the Hammersmith Functional Motor Scale-Expanded (HFMSE) after 15 months of nusinersen treatment (least-squares mean increase of 4 points). ${ }^{26}$ In contrast, patients who received the sham procedure showed loss of motor function over the same interval (least-squares mean decrease of 1.9 points). As a result, the study was terminated early, and patients were also enrolled in the open-label study. ${ }^{26}$

Another ongoing open-label study is evaluating the efficacy and safety of nusinersen given before SMA symptom onset. This trial has enrolled 25 infants younger than 6 weeks with genetically diagnosed SMA and 2 to 3 copies of SMN2 (likely to develop SMA1 or SMA2, respectively, if untreated). ${ }^{14,27}$ At a 25-month interim analysis, all patients were alive and required neither tracheostomy nor permanent ventilation-in distinct contrast to expected outcomes based on natural history (e.g., for SMAl without intervention, median survival and/or time to ventilation dependence $\geq 16$ hours was 13.5 months). In addition, all patients achieved the motor milestone of sitting unsupported, an achievement not previously observed in SMA1, and the majority could walk. ${ }^{27}$

In sham-controlled studies, a small proportion of individuals treated with nusinersen showed mild elevations in urinary protein and low platelet counts. ${ }^{28}$ The overall incidence of adverse events was similar between treatment and sham groups, and severe adverse events were lower in the treatment group compared with the sham group., ${ }^{4,26}$ Rates of lumbar puncture-related complications in the treatment groups were similar to those reported in association with lumbar puncture and included postspinal puncture headache and local pain.,26 Difficulty administering treatment for some individuals, such as those with severe scoliosis or spinal fusion, along with cost ( $\$ 125,000$ per dose) and frequency of dosing (4 doses in the first 2 months, then 1 dose every 4 months thereafter) are ongoing challenges with nusinersen. ${ }^{29,30}$

Although nusinersen is not a cure, the clinical trials demonstrated greater improvement in functional outcomes with earlier treatment. ${ }^{4,26}$ This highlights a need for early, presymptomatic diagnosis, which is possible through newborn screening for SMA. In August 2018, the U.S. Health and Human Services Secretary signed the recommendation that newborn screening for SMA be added to the Recommended Uniform Screening Panel. ${ }^{31}$ To date, newborn screening is available in just a few states, and access will be more widespread in the near future.

\section{Small Molecules}

Several oral small molecules are in early phase 1-3 clinical trials after showing promise in preclinical studies. These include 2 mRNA splicing correctors, branaplam (LMI070) and risdiplam (RG7916), and a fast-skeletal muscle troponin activator, reldesemtiv (CK-2127107). $7,32,33$ 


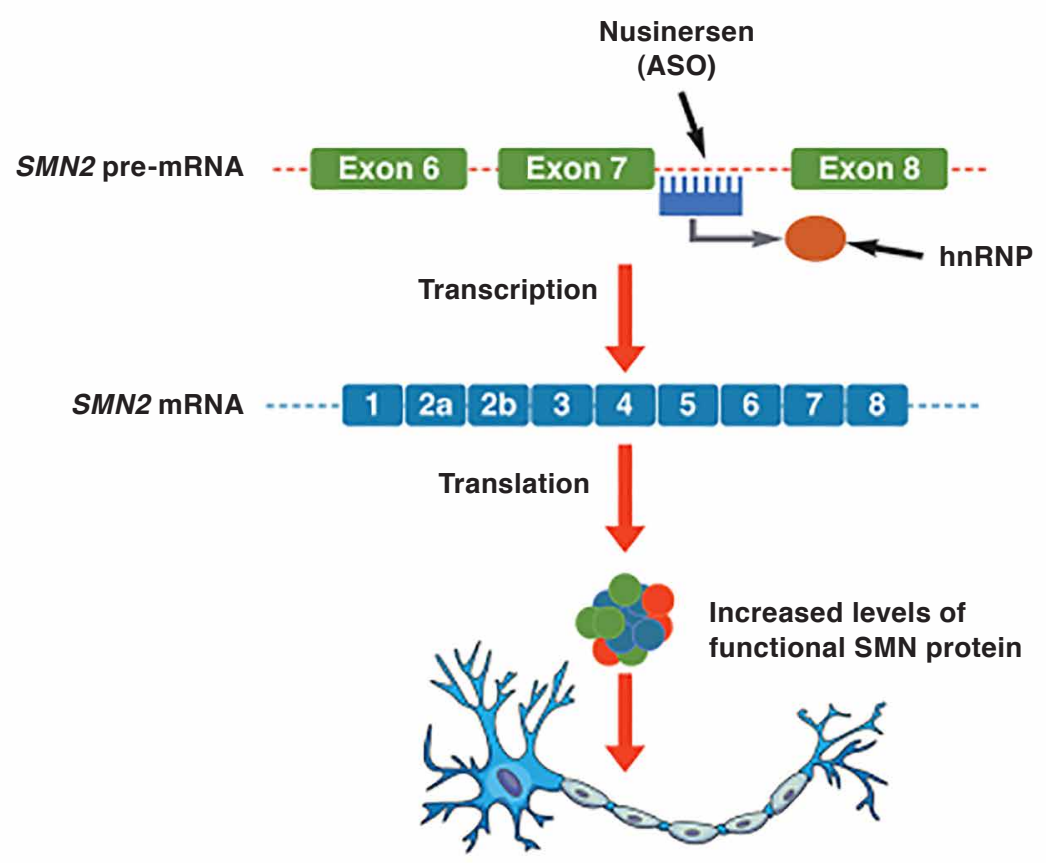

Adapted from: Farrar MA, Park SB, Vucic S, et al. Emerging therapies and challenges in spinal muscular atrophy. ${ }^{7}$

Note: Nusinersen, an antisense oligonucleotide (ASO), binds to a splicing silencer region on SMN2 pre-mRNA. This displaces a splicing repressor protein, heterogeneous ribonucleoprotein (hnRNP), and increases incorporation of exon 7 in the $m R N A$ transcript. The result is increasing levels of both full-length SMN $m R N A$ and fully functional SMN protein.

SMN = survival motor neuron.

Both branaplam and risdiplam work by promoting inclusion of exon 7 in SMN2 mRNA, thereby increasing levels of SMN protein. Recruiting for a first-in-human trial for branaplam began several years ago, and preliminary findings hinted at efficacy and safety, ${ }^{33}$ but the trial was suspended temporarily because of nerve injury observed in a parallel, preclinical toxicology study. ${ }^{32}$ The problem has since been resolved, recruiting has resumed, and the study continues. ${ }^{32}$

Risdiplam is under study in several trials, including FIREFISH (a phase $2 / 3$ open-label study involving patients with SMAl ages 1-7 months) and SUNFISH (a phase $2 / 3$, placebocontrolled study involving patients ages $2-25$ years with SMA2 or SMA3). ${ }^{34,35}$ Results to date show that risdiplam is well tolerated and increases blood levels of SMN protein. In addition, after 8 months of treatment, many infants in the FIREFISH study achieved improvements on motor milestones, as assessed using the HINE section 2 and the Children's Hospital of Philadelphia Infant Test of Neuromuscular Disorders (CHOP INTEND); further, none of the infants required tracheostomy, had to be placed on permanent ventilation, or lost the ability to swallow. ${ }^{35}$ Patients in the SUNFISH trial showed stabilization or improvement in motor function, as assessed using the Motor Function Measure-32; a greater percentage of younger patients (ages 2-11 years, 77\%) than older patients (ages 12-24 years, $46 \%)$ showed motor function improvements. ${ }^{34}$

Reldesemtiv works by increasing the sensitivity of the sarcomere to calcium, essentially reducing fatigue. ${ }^{7}$ A phase 2, randomized, double-blind, placebo-controlled trial has tested this agent in adolescents and adults ( $\geq 12$ years) with SMA2, SMA3, or SMA4. ${ }^{36}$ After 8 weeks of treatment, reldesemtiv was associated with increases from baseline on 6-minute walk distance (a test of aerobic capacity and endurance) and maximal expiratory pressure (a test of respiratory muscle strength). No differences were seen, however, on a number of other tests, including the HFMSE and a test of mobility (timed up-and-go). Adverse events were similar in treatment and placebo groups. Additional studies are in planning stages and may include patients already taking another disease-modifying therapy. ${ }^{36}$

\section{AVXS-101 Clinical Trial}

Years of progress in gene therapy (see the sidebar) set the stage for its development and application in SMA. Investigators designed a vector-called scAAV9.CB.SMN in early studies, 
TABLE 2 Select Neurological Function Assessments Used in SMA Clinical Trials

\begin{tabular}{|c|c|}
\hline Measure & Description \\
\hline $\begin{array}{l}\text { Hammersmith Infant Neurologic } \\
\text { Exam (HINE Section 2) }\end{array}$ & $\begin{array}{l}\text { - Used for assessing various aspects of neurologic function in infants ages } 2 \text { months to } 2 \text { years } \\
\text { - } 3 \text { sections, } 26 \text { items } \\
\text { o Section 1: Neurologic assessment } \\
\text { o Section 2: Developmental milestone assessment } \\
\text { o Section 3: Behavioral assessment } \\
\text { - Section } 2 \text { may be used alone } \\
\text { o } 8 \text { items, scores of } 0 \text { to } 2,3 \text {, or } 4 \\
\text { o Children with SMAl may score } 0 \text { on all } 8 \text { items }\end{array}$ \\
\hline $\begin{array}{l}\text { Hammersmith Functional Motor } \\
\text { Scale, Expanded (HFMSE) } 85,86\end{array}$ & $\begin{array}{l}\text { - Used to evaluate motor function in individuals with later-onset SMA (SMA2 and SMA3) } \\
\text { - } 33 \text { items } \\
\text { - Total score ranges from } 0 \text { to } 66 \text {; lower scores indicate poorer function } \\
\text { - Scores in patients with SMA2 or SMA3 may decline over } 12 \text { months }\end{array}$ \\
\hline $\begin{array}{l}\text { Children's Hospital of Philadelphia } \\
\text { Infant Test of Neuromuscular } \\
\text { Disorders (CHOP INTEND) } 87,88\end{array}$ & $\begin{array}{l}\text { - Used to evaluate motor skills of children with SMA ages } \sim 4 \text { months to } 4 \text { years } \\
\text { - Includes } 16 \text { items to assess motor skills, each graded on a scale of } 0 \text { (no response) to } 4 \text { (complete response) } \\
\text { - Total score ranges from } 0 \text { to } 64 \text {; lower scores indicate poorer function } \\
\text { - Infants with SMA may score much lower than unaffected infants } \\
\text { - A score exceeding } 40 \text { is rarely seen in infants with SMAl }\end{array}$ \\
\hline $\begin{array}{l}\text { Motor Function Measure-32 Item } \\
(\text { MFM-32) }\end{array}$ & $\begin{array}{l}\text { - Used to evaluate motor function in children and adults with neuromuscular diseases } \\
\text { - Assesses } 32 \text { items in } 3 \text { dimensions (standing and transfers, axial and proximal motor function, distal motor function) } \\
\text { - Total score ranges from } 0 \text { to } 96 \text {; lower scores indicate poorer function }\end{array}$ \\
\hline
\end{tabular}

now known as AVXS-101-that carries DNA-encoding, fully functional human SMN under control of a continuous promoter. The vector is designed to boost levels of SMN protein (Figure 4). Preclinical studies demonstrated efficacy and safety in mice and nonhuman primate models of SMA, paving the way for the first clinical trial in humans. ${ }^{60,61}$

\section{Gene Therapy}

In the nearly 50 years since the concept of gene therapy was first put forth, ${ }^{37}$ its use in humans has been met with overt enthusiasm as well as guarded concern. Gene therapy can target specific mutations to ameliorate or potentially cure disease. Approaches include replacing a mutated gene with a healthy gene, inactivating or "knocking out" a malfunctioning gene, or providing a missing gene. Pioneering studies conducted in the late 1990s were marred by serious adverse effects, including inflammatory responses to vectors and malignancies related to proto-oncogene activation. ${ }^{38}$ Despite these setbacks, the field moved forward with research to better understand mechanisms of vector delivery, mitigate host responses to vectors, and enhance clinical trial safety protocols. Improvements in tools, technologies, and safety ushered in gene therapy trials for congenital blindness, hemophilia, immunodeficiencies, cancer, and neuromuscular diseases. ${ }^{39}$ Several gene therapies have since been approved, including
This was a single center, open-label trial designed primarily to study safety of a single intravenous dose of AVXS-101, and secondarily to assess efficacy of the treatment in children with SMA1 and 2 copies of SMN2. ${ }^{5}$ Sixteen children were screened; 1 was excluded because of persistent elevation of anti-AAV9 antibody titers. There were 2 treatment cohorts: patients in

voretigene neparvovec (Luxturna) for treatment of Leber congenital amaurosis, and tisagenlecleucel (Kymriah) and axicabtagene ciloleucel (Yescarta) for treatment of certain B-cell cancers. ${ }^{40-42}$

Vectors such as lentiviruses and adeno-associated viruses (AAV) carrying the gene of interest have shown great promise. Lentiviral vectors can carry relatively large (up to $\sim 8 \mathrm{~kb}$ ), complex genes (such as beta-globin genes). ${ }^{39,43,44}$ They also integrate preferentially into coding regions of the host gene, unlike the gamma retroviral vectors of the 1980s and early 1990s, which integrated into noncoding promoter and enhancer regions, increasing the risk of oncogenic mutagenesis. ${ }^{45}$ Lentiviral vectors have proven useful, for example, in the treatment of certain hemoglobinopathies as well as the metabolic disorder adrenoleukodystrophy and the lysosomal storage disease metachromatic leukodystrophy. ${ }^{46-48}$

(continued on next page) 


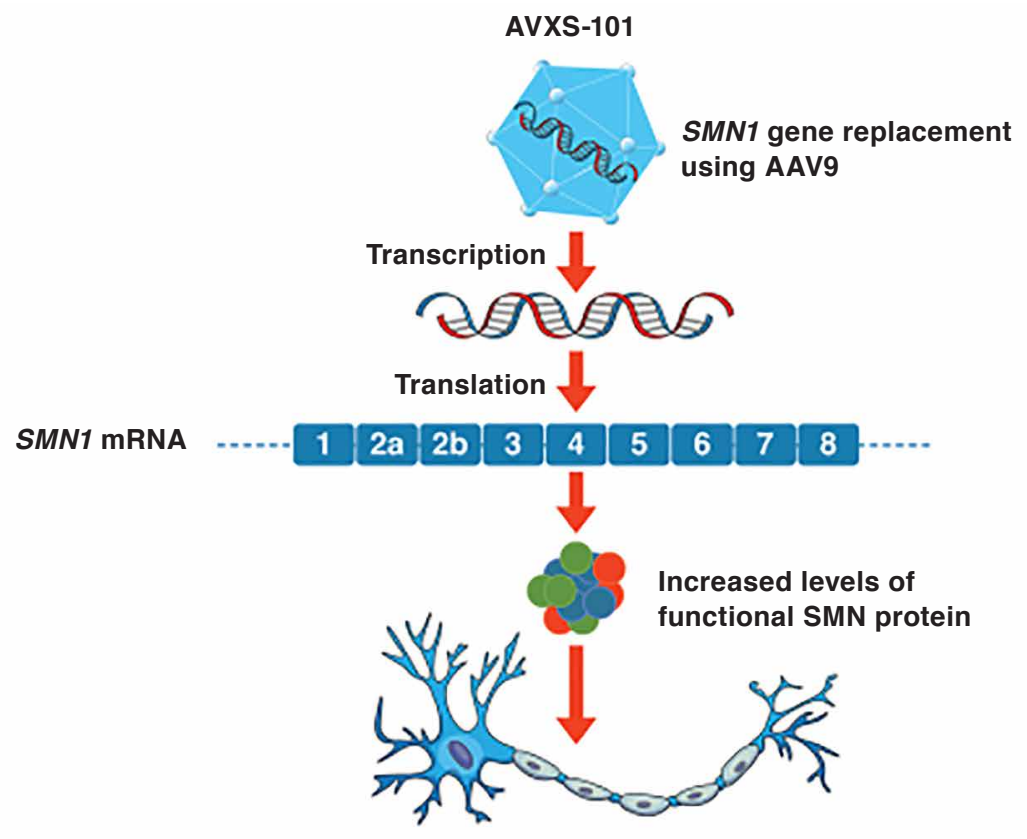

Adapted from: Farrar MA, Park SB, Vucic S, et al. Emerging therapies and challenges in spinal muscular atrophy. ${ }^{7}$

Note: AVXS-101 is a self-complementary AAVP (scAAV9) vector that carries full-length SMN1 cDNA under control of a continuous promoter. Inside the cell, it is rapidly transcribed to SMN1 mRNA, which is then translated to full-length, fully functional SMN protein.

SMN = survival motor neuron.

cohort 1 ( $\mathrm{n}=3$, mean age 6.3 months) received a low dose of AVXS-101 $\left(6.7 \times 10^{13} \mathrm{vg}\right.$ per $\left.\mathrm{kg}\right)$; those in cohort $2(\mathrm{n}=12$, mean age 3.4 months) received a higher dose $\left(2.0 \times 10^{14} \mathrm{vg}\right.$ per $\left.\mathrm{kg}\right)$. Treatment was infused intravenously over 60 minutes.

\section{Gene Therapy (continued)}

$A A V$ vectors have been engineered from a nonpathogenic, naturally nonreplicating parvovirus. A "cassette" containing the gene of interest replaces all viral DNA sequences-the lack thereof ensures that the vector does not integrate into host DNA. ${ }^{49}$ Following entry into the host cell and transport to the nucleus, the transferred DNA remains there in a stable episomal form.

The mid-1990s saw successful gene transfer using these vectors in mice. ${ }^{50,51}$ Subsequent studies demonstrated that $\mathrm{AAV}$ vectors can transduce a wide variety of target cells in various animals, with specific tropism for tissues such as liver, retina, and even the central nervous system. ${ }^{52}$ Safety in humans was first demonstrated in hemophilia B trials conducted in the late 1990 s. ${ }^{53,54}$
At the time of initial publication, all patients had reached at least 20 months of age without needing permanent ventilation. ${ }^{5}$ All patients demonstrated increases from baseline in scores on the CHOP INTEND. The mean increase was 7.7 points in

AAV vectors have limitations, such as not being able to package more than $\sim 5 \mathrm{~kb}$ of DNA. ${ }^{55}$ In addition, because they do not integrate into host DNA, long-term expression is limited to nondividing cells, which may be less than optimal for some diseases. However, in one study, transgene expression in the human brain was found to persist as long as 10 years after initial administration. ${ }^{56}$ Emergence of large-scale manufacturing and purification techniques have allowed for largeanimal studies and multicenter clinical trials. ${ }^{57}$ Research into immune responses to the viral capsid (and strategies to overcome them) has been central to understanding their full potential. ${ }^{58}$ Finally, redesigning AAV vector genomes to be self-complementary (scAAVs) has reduced dependence on host cell transcription and improved speed and efficiency of therapeutic protein synthesis. ${ }^{59}$ 
Gene Therapy for Spinal Muscular Atrophy: An Emerging Treatment Option for a Devastating Disease

TABLE 3

10 Lessons Learned from Commercialization of Nusinersen

1. Anticipate delays because of unknowns of the therapy (e.g., REMS requirements, care setting for administration) before product launch, to avoid inefficiencies during the formulary review process; the time to address unforeseen obstacles is amplified by each step of formulary review. This is especially important for therapies where age or weight cut-offs are likely to be imposed on the approved labeling.

2. Provide education to address concerns or misconceptions about gene therapy (such as doubts about efficacy and safety that linger from early trials), to ensure safe and efficient delivery of care.

3. Engage in collaboration and knowledge-sharing with local and regional providers early to assist in developing care-delivery mechanisms.

4. Ensure that stakeholders thoroughly understand the processes involved in adding complex, high-cost therapies to their health system formularies to maintain trust and support shared decision-making among colleagues.

5. Continue and improve upon a patient-focused system of advanced care.

6. Promote engagement between senior leadership and clinical specialists requesting formulary additions, to ensure that provision of these therapies aligns with the system's overall mission. This interaction should facilitate better connection with patient care and, consequently, with patients themselves.

7. Ensure that decision-making bodies communicate the scope of their authority before any formulary evaluation. Providing clear expectations of what it means to add or deny an item to the formulary system can help avoid miscommunication throughout the process and assist in the resolution of conflicts.

8. Recognize that conditions requiring the therapy are frequently devastating to patients and their families. Providers involved with patient care should act as their champions while understanding the consequences of limited health care resources when a system provides high-cost therapies. The primary provider should appreciate the methodical approach that is required to responsibly add therapies to the formulary.

9. Establish a multidisciplinary committee that includes patient representatives, ethicists, finance experts, senior leadership, and chairs/leaders from multiple clinical disciplines to accept accountability for advising the system on major formulary decisions. This committee works together with the P\&T committee to ensure shared decision-making and stakeholder engagement throughout the evaluation process.

10. Strive to avoid or reduce the time between potential FDA approval and payer coverage determinations (i.e., when reimbursement is possible) Unfortunately, delays are inevitable and often outside of the provider's control. To assist both providers and patients during this period, senior leadership should consistently engage staff and the community to provide updates and direction.

FDA =U.S. Food and Drug Administration; PET = pharmacy and therapeutics; REMS = Risk Evaluation and Mitigation Strategy.

cohort 1 (from a mean baseline of 16.3 points) and 24.6 points in cohort 2 (from a mean baseline of 28.2). These gains were maintained throughout study duration. Eleven children in cohort 2 were able to sit without support for at least 5 seconds; 11 achieved head control; 9 could roll over. Two could crawl, pull to stand, stand, and walk independently; 11 achieved the ability to speak. No children in prior natural history studies had gained these motor milestones. ${ }^{11,12}$ Data updates after 24 months showed continued survival and improvement in motor function. ${ }^{62}$ In addition, as observed in nusinersen trials, the earlier the treatment, the better the outcomes; generally, those treated at the youngest ages made the greatest gains, while the patients treated the latest showed the least improvement. ${ }^{5}$

Adverse events observed with AVXS-101 were mostly unrelated to treatment. However, 1 patient in cohort 1 had treatmentrelated elevations in liver transaminases (31 times the upper limit of normal for alanine aminotransferase and 14 times the upper limit of normal for aspartate aminotransferase); these elevations responded to prednisolone, which was subsequently given to all other patients as part of the treatment protocol. One patient in cohort 2 had similar elevations in liver enzymes and required additional prednisolone. Transaminase elevations were not associated with other liver function abnormalities or clinical changes, and treatment with AVXS-101 appears safe overall. ${ }^{5}$

Several additional multicenter trials of AVXS-101 are underway. One ongoing trial is a phase 3, open-label, single-arm, single-dose trial of intravenous AVXS-101 in symptomatic children aged $<6$ months with type 1 SMA and 1 to 2 copies of SMN2 (NCT03306277). ${ }^{63}$ Another trial involves infants aged $<6$ weeks, before onset of SMA symptoms, with a biallelic deletion of SMN1 and 2, 3, or 4 copies of SMN2 (NCT03505099); they, too, will receive a single intravenous dose of the study drug. ${ }^{64}$ A third trial is studying single-dose intrathecal administration of AVXS-101 in 2 cohorts of children with 3 copies of SMN2 who are sitting but not standing. Cohort 1 includes children aged $<2$ years, and cohort 2 includes children aged $\geq 2$ and $<5$ years (NCT03381729). ${ }^{65} \mathrm{~A}$ fourth trial, still in planning, will be an "all-comers" study enrolling patients with SMA who are aged between approximately 6 months and 18 years and do not qualify for other clinical trials. ${ }^{66}$ The FDA has granted AVXS-101 orphan drug designation for all types of SMA, and breakthrough therapy and fast track designations for the treatment of SMAl ${ }^{67}$ Further, the first request for FDA approval-a biologics license application (BLA) for use of AVXS-101 in infants with SMAl up to 9 months of age-was submitted in October 2018, and requests for older patients and other SMA types are anticipated. ${ }^{6}$ If the FDA accepts the BLA (a decision is expected within 60 days), review is expected to take 6 months. Thus, approval may be fairly imminent.

\section{Anticipating Availability of Gene Therapy for SMA:} How Do Hospitals and Health Care Systems Need to Prepare?

Approval of novel therapies for rare and untreated conditions have been trending upward in recent years, and in 2017, 39\% 
(18 of 46) of the drugs and biologics approved by the FDA's Center for Drug Evaluation and Research had orphan drug status. ${ }^{68,69}$ These therapies for rare and ultrarare conditions continue to challenge the traditional paradigm of maintaining a health system formulary consisting only of medications appropriate for routine use, as recommended by the 2008 American Society of Health-System Pharmacists' Guidelines on the Pharmacy and Therapeutics Committee and the Formulary System..$^{70}$ Consideration of an institution's formulary system is important, as it is the pivotal drug management tool to maintain high-quality care while minimizing health system costs. In principle, formulary systems are designed to assist in clinical decision-making by ensuring access to efficacious, safe, and cost-effective medications; although certain practical components may differ, these founding principles should guide the evaluation process for all novel therapies. ${ }^{71}$

\section{Potential Effects of Cost on Adoption of New Therapies}

In the United States, health care practitioners must function within a system that promotes a difficult duality. The FDA supports 2 seemingly disparate goals: fostering market-based incentives for drug manufacturers (e.g., unregulated marketentry drug pricing) while ensuring public access to affordable medications. ${ }^{72}$ Many health care systems, especially those also acting as the payer, experience only the costs of innovative therapies and must further operationalize provision of these typically complex therapies.

The revolutionary potential of gene therapy-to bring cure to what is otherwise incurable-likely plays a large role in determination of market-entry pricing. ${ }^{73}$ Indeed, the substantial costs associated with nusinersen and those expected with AVXS-101 have raised concerns from providers and payers alike (see Table 3 for useful lessons learned from commercialization of nusinersen). ${ }^{73,74}$ Further confounding the determination of drug value are the small populations studied, alternative trial designs employed, and short follow-up durations reported; these are all factors that decrease the certainty of safety and efficacy. Since health care practitioners are accustomed to the FDA's gold standard of large randomized controlled trials supporting drug approval, this uncertainty, along with comparatively high market-entry prices (e.g., ranging from $\$ 373,000$ to $\$ 850,000$ for one-time treatment with currently approved gene therapies $^{75-77}$ ), inevitably turn the focus of conversation to drug cost. Yet too great an emphasis on cost of therapy without fair consideration of its benefits may block or delay access to care..$^{74,78}$

Ultimately, providers must implement a strategic and methodical approach to formulary management to ensure accessible care while avoiding unrecoverable financial consequences. Guiding this approach should be consideration of patient benefit from therapy, including improved quality of life and function and decreased health care utilization and hospitalizations, while giving due credence to the balancing act a payer needs to engage with in respect to financial resource allocation. Whatever the financial climate, health system leaders should navigate the formulary evaluation process with diligence to maximize the likelihood of making beneficial therapies available. Participation of various stakeholders across the health care spectrum in the formulary decision-making process would increase the chances of a balanced viewpoint.

\section{Steps in Getting Gene Therapy on Formulary}

Formulary evaluation and addition of AVXS-101 (or other gene therapies) should be as methodical as that for routinely used medications, despite the potential for infrequent use.

A proactive pipeline-monitoring approach to ensure adequate lead time for evaluating innovative treatments can help systems anticipate future product availability. For most institutions, this task is delegated to the pharmacy department or (if established) a drug information center, and close collaboration with clinical specialists helps to guide selection of potential formulary additions. Table 3 lists lessons learned from implementation of nusinersen, the first treatment approved for SMA. Table 4 provides a checklist and illustrates a possible pathway from anticipation of availability to implementation of clinical use for AVXS-101.

Once a therapy is identified for formulary addition, a team should be established to oversee development of information and clinical support tools (e.g., clinical practice guidelines, therapy administration policies, standard operating procedures) that are readily accessible and ensure a uniform and efficient medicationuse process within the system. Early involvement of health informatics specialists is advised to ensure safe and timely integration of the therapy into the electronic health record.

In most settings, oversight for formulary evaluation is provided by a pharmacy and therapeutics (P\&T) committee; however, delegation to a specialized subcommittee may be required.$^{70}$ Such subcommittees are often needed to assist with formulary management. They provide focused representation to address complexities in specific areas (e.g., oncology, neurology, infectious diseases); without them, evaluation of medication use would be limited in scale and scope. Similarly, stewardship programs may be developed to facilitate the safe and appropriate use of medications within health systems, the archetype being the antimicrobial stewardship program frequently implemented across institutions and supported by evidence of beneficial clinical and economic outcomes. ${ }^{79}$ In addition, institutions may establish multidisciplinary subcommittees that specifically evaluate products granted accelerated approval or designated as orphan or breakthrough therapies. Members should include patient representatives, physician leaders from various specialties, finance representatives, ethics representatives, and senior leadership representatives (e.g., chief medical officer, chief executive officer, or chief of staff) to ensure shared decision-making and stakeholder engagement throughout the evaluation process. 
$\square$ Inform the appropriate decision-making bodies (e.g., P\&T, medical board) about the anticipated therapy to start a transparent flow of information. Petitioning leadership to allocate resources to the formulary review process before possible FDA approval may be needed to ensure minimal time between approval and a formulary addition decision.

$\square$ Determine the effects of providing therapy on patients, providers, and the health system, with consideration of potential effects on standards of care (e.g., frequency of patient visits), implications of SMA inclusion in the Recommended Uniform Screening Panel, any significant unknowns of efficacy or safety (e.g., durability of effect, benefit for children and adults with type 2, 3, or 4 SMA), and other factors. Addressing these issues early may expedite the formulary review process.

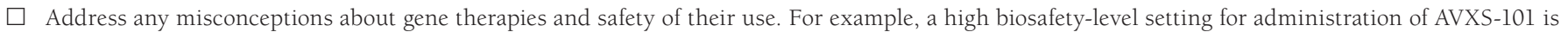
unnecessary and would add excessive burden.

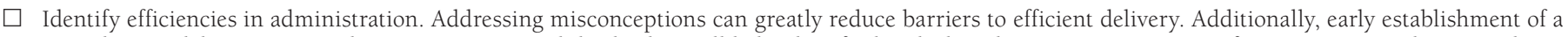
gene therapy delivery team and communication with leadership will help identify the ideal medication-use system. Performing a gap analysis can then allow staff to address additional potential barriers.

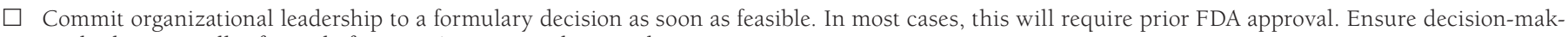
ing bodies are well informed of any FDA review updates or decisions.

$\square$ Consider additional unknowns requiring a flexible formulary review process. These include regulatory approval, specifics of label, cost, and product availability timeline. By engaging in the review process early and developing novel ways to address these unique issues, a system will be better prepared for AVXS-101 and future gene therapies.

arganizations can follow the same general steps when preparing for AVXS-101 availability irrespective of clinical trial site status.

FDA = U.S. Food and Drug Administration; PET= pharmacy and therapeutics; SMA = spinal muscular atrophy.

Regardless of variations in the committees and subcommittees involved, several universal strategies direct medication use within health systems. These include establishment of specificuse criteria (e.g., predefined patient clinical criteria that must be met); restrictions criteria (e.g., highly trained individuals for prescribing or a specialized service for administering) for discontinuation of therapy; development of clinical practice guidelines; and requirement of approval by a medical director, division chair, or other clinical leader. Traditional strategies will be deployed, as well, to ensure appropriate use of gene therapies.

Strict external regulations governing use of these therapies are expected given their specialized nature. Designees to oversee implementation of and adherence to regulations, such as requirements of the Risk Evaluation and Mitigation Strategy (REMS) program, should be appointed well in advance of the formulary addition, as audits are likely to occur within the first 6-12 months of therapy provision.

\section{Working with Payers}

The focus on cost, despite the potential and perceived benefits of novel therapies, is inevitable when considering a health system's revenue cycle. For most providers, the margin of error is essentially zero for the inappropriate use of a costly therapy (e.g., one $12 \mathrm{mg}$ dose of nusinersen is $\$ 125,000$ based on wholesale acquisition cost). ${ }^{80}$ Unlike routinely used treatments, for which occasional misadministration and subsequent loss of reimbursement is tolerable, a single misstep could have grave financial implications. Establishment of comprehensive processes for medication use is required to prevent systemic issues that risk multiple misadministrations. In addition, errors in use could represent missed opportunities to provide potentially beneficial therapies.

Early collaboration between health systems and payers is critical to the health system's process for evaluating novel therapies. Despite increasing numbers of approved orphan drugs, in 2016, these treatments accounted for 7.9\% of overall drug spending, and $1.6 \%$ were priced at $>\$ 500,000$ per year. ${ }^{69}$ At the same time, growth in orphan drug spending is decreasing relative to nonorphan drug spending. ${ }^{69}$ Payers are frequently implementing strict reimbursement practices in an effort to contain costs and maintain member benefits. Investigation into the reimbursement landscape should occur in tandem with review of clinical safety and efficacy; this may include consultation with local private payers and state Medicaid programs, review of national coverage determinations from the Centers for Medicare \& Medicaid Services, and consideration of potential drug administration sites such as those eligible for the 340B Drug Pricing Program. ${ }^{81}$ Once reimbursement potential is determined, collaboration with internal finance teams to model the expected patient and payer mix could provide insight into the revenue cycle effects of adding a high-cost formulary item. Involvement of finance teams is also critical for identifying all potential avenues for reimbursement, such as new technology add-on payments. ${ }^{82}$

\section{Summary}

SMA is an autosomal recessive disease caused by deficiency in SMN protein that can lead to disability and death. Thus, it 
is a devastating diagnosis for families, particularly in its most severe form. However, a new treatment, nusinersen, is available, and others are emerging, including a promising new gene therapy, AVXS-101. In patients with SMA, both treatments are most effective if given early, before the onset of extensive nerve damage and associated symptoms. Still, there is evidence to support their use in improving or stabilizing disease after symptoms appear. Clinical trials are ongoing, but at this time, AVXS-101 may have an advantage of a single intravenous administration. If it receives FDA approval, both payers and providers will need to be prepared for its implementation. The future seems bright, but many steps remain; careful planning with attention to principles of sound formulary practice may help limit gaps between approval and access.

\section{REFERENCES}

1. Sugarman EA, Nagan N, Zhu H, et al. Pan-ethnic carrier screening and prenatal diagnosis for spinal muscular atrophy: clinical laboratory analysis of > 72,400 specimens. Eur J Hum Genet. 2012;20(1):27-32.

2. Swoboda KJ, Prior TW, Scott CB, et al. Natural history of denervation in SMA: relation to age, SMN2 copy number, and function. Ann Neurol. 2005;57(5):704-12.

3. Oskoui M, Levy G, Garland CJ, et al. The changing natural history of spinal muscular atrophy type 1. Neurol. 2007;69(20):1931-36.

4. Finkel RS, Mercuri E, Darras BT, et al; ENDEAR Study Group. Nusinersen versus sham control in infantile-onset spinal muscular atrophy. $N$ Engl J Med. 2017;377(18):1723-32.

5. Mendell JR, Al-Zaidy S, Shell R, et al. Single-dose gene-replacement therapy for spinal muscular atrophy. N Engl J Med. 2017;377(18):1713-22.

6. Cure SMA. AveXis files for FDA approval of gene therapy for spinal muscular atrophy type I. October 18, 2018. Available at: http://www.curesma. org/news/avexis-fda-approval-type-i.html. Accessed November 30, 2018.

7. Farrar MA, Park SB, Vucic S, et al. Emerging therapies and challenges in spinal muscular atrophy. Ann Neurol. 2017;81(3):355-68.

8. Harding BN, Kariya S, Monani UR, et al. Spectrum of neuropathophysiology in spinal muscular atrophy type I. J Neuropathol Exp Neurol. 2015;74(1):15-24.

9. Arnold WD, Kassar D, Kissel JT. Spinal muscular atrophy: diagnosis and management in a new therapeutic era. Muscle Nerve. 2015;51(2):157-67.

10. Verhaart IEC, Robertson A, Wilson IJ, et al. Prevalence, incidence and carrier frequency of 5q-linked spinal muscular atrophy—a literature review. Orphanet J Rare Dis. 2017;12(1):124.

11. Kolb SJ, Coffey CS, Yankey JW, et al; NeuroNEXT Clinical Trial Network on behalf of the NN101 SMA Biomarker Investigators. Natural history of infantile-onset spinal muscular atrophy. Ann Neurol. 2017;82(6):883-91.

12. Finkel RS, McDermott MP, Kaufmann P, et al. Observational study of spinal muscular atrophy type I and implications for clinical trials. Neurology. 2014:83(9):810-17.

13. Iannaccone ST. Modern management of spinal muscular atrophy. J Child Neurol. 2007;22:974-78.

14. Chung BH, Wong VC, Ip P. Spinal muscular atrophy: survival pattern and functional status. Pediatrics. 2004;114(5):e548-53

15. Lefebvre S, Bürglen L, Reboullet S, et al. Identification and characterization of a spinal muscular atrophy-determining gene. Cell. 1995;80(1):155-65.
16. Wirth B, Herz M, Wetter A, et al. Quantitative analysis of survival motor neuron copies: identification of subtle SMNl mutations in patients with spinal muscular atrophy, genotype-phenotype correlation, and implications for genetic counseling. Am J Hum Genet. 1999;64(5):1340-56.

17. Mercuri E, Finkel RS, Muntoni F, et al; SMA Care Group. Diagnosis and management of spinal muscular atrophy: part 1: recommendations for diagnosis, rehabilitation, orthopedic and nutritional care. Neuromuscul Disord. 2018;28(2):103-15.

18. Harada Y, Sutomo R, Sadewa AH, et al. Correlation between SMN2 copy number and clinical phenotype of spinal muscular atrophy: three SMN2 copies fail to rescue some patients from the disease severity. J Neurol. 2002;249(9):1211-19.

19. Prior TW, Krainer AR, Hua Y, et al. A positive modifier of spinal muscular atrophy in the SMN2 gene. Am J Hum Genet. 2009;85(3):408-13.

20. Cuscó I, Barceló MJ, Rojas-García R, et al. SMN2 copy number predicts acute or chronic spinal muscular atrophy but does not account for intrafamilial variability in siblings. J Neurol. 2006;253(1):21-25.

21. DiVito D, Konek S. Spinal muscular atrophy: summary for nutritional care. Infant Child Adoles Nutr. 2010;2(6):348-54

22. Wang CH, Finkel RS, Bertini ES, et al; Participants of the International Conference on SMA Standard of Care. Consensus statement for standard of care in spinal muscular atrophy. J Child Neurol. 2007;22(8):1027-49.

23. Singh NK, Singh NN, Androphy EJ, Singh RN. Splicing of a critical exon of human survival motor neuron is regulated by a unique silencer element located in the last intron. Mol Cell Biol. 2006;26(4):1333-46.

24. Hua Y, Vickers TA, Okunola HL, Bennett CF, Krainer AR. Antisense masking of an hnRNP Al/A2 intronic splicing silencer corrects SMN2 splicing in transgenic mice. Am J Hum Genet. 2008;82(4):834-48.

25. Bennett CF, Baker BF, Pham N, Swayze E, Geary RS. Pharmacology of antisense drugs. Annu Rev Pharmacol Toxicol. 2017;57:81-105.

26. Mercuri E, Darras BT, Chiriboga CA, et al; CHERISH Study Group. Nusinersen versus sham control in later-onset spinal muscular atrophy. N Engl J Med. 2018;378(7):625-35.

27. Cure SMA. New Spinraza data presented at annual congress of the World Muscle Society demonstrate benefits in treating presymptomatic infants with SMA. October 8, 2018. Available at: http://www.curesma.org/news/ spinraza-data-fall2018.html. Accessed November 30, 2018.

28. Spinraza (nusinersen) injection, for intrathecal use. Biogen. Revised December 2016. Available at: https://www.accessdata.fda.gov/drugsatfda_ docs/label/2016/209531lbl.pdf. Accessed December 1, 2018.

29. Mousa MA, Aria DJ, Schaefer CM, et al. A comprehensive institutional overview of intrathecal nusinersen injections for spinal muscular atrophy. Pediatr Radiol. 2018;48(12):1797-805.

30. Aartsma-Rus A. FDA approval of nusinersen for spinal muscular atrophy makes 2016 the year of splice modulating oligonucleotides. Nucleic Acid Ther. 2017:27(2):67-69

31. Cure SMA. HHS Secretary, Alex Azar, recommends nationwide newborn screening for SMA. July 3, 2018. Available at: http://www.curesma.org/news/ nbs-update-july2018.html. Accessed November 30, 2018.

32. Shorrock HK, Gillingwater TH, Groen EJN. Overview of current drugs and molecules in development for spinal muscular atrophy therapy. Drugs. 2018;78(3):293-305

33. Charnas L. Safety and efficacy findings in the first-in-human trial of the oral splice modulator branaplam in type 1 spinal muscular atrophy (SMA): interim results. Presented at: the 21st Annual Spinal Muscular Atrophy Researcher Meeting; June 29-July 2, 2017; Orlando, FL.

34. Mercuri E, Baranello G, Kirschner J, et al. SUNFISH Part 1. Risdiplam (RG7916) treatment results in a sustained increase of SMN protein levels and improvement in motor function in patients with type 2 or 3 SMA. Presented at: the 23rd International Annual Congress of the World Muscle Society; October 2-6, 2018; Mendoza, Argentina. 
35. Baranello G, Servais L, Day JW, et al. FIREFISH: Risdiplam (RG7916) improves motor function in babies with type 1 SMA. Presented at: the 23rd International Annual Congress of the World Muscle Society; October 2-6, 2018; Mendoza, Argentina.

36. Cure SMA. Cytokinetics presents data from the phase 2 clinical trial of reldesemtiv (CK-2127107) in patients with SMA at the 2018 Annual SMA Conference. June 16, 2018. Available at: http://www.curesma.org/news/ cytokinetics-data-june-2018.html. Accessed November 30, 2018.

37. Friedmann T, Roblin R. Gene therapy for human genetic disease? Science. 1972;175(4025):949-55.

38. Jenks S. Gene therapy death-"everyone has to share in the guilt." J Natl Cancer Inst. 2000;92(2):98-100.

39. Dunbar CE, High KA, Joung JK, Kohn DB, Ozawa K, Sadelain M. Gene therapy comes of age. Science. 2018;359(6372). pii: eaan4672.

40. Luxturna (voretigene neparvovec-rzyl) intraocular suspension for subretinal injection. Spark Therapeutics. Revised January 2018. Available at: https://dailymed.nlm.nih.gov/dailymed/drugInfo.cfm?setid=08313a24-e7ce457a-bb3f-16lbc45517ee. Accessed December 19, 2018.

41. Kymriah (tisagenlecleucel) suspension for intravenous infusion. Novartis Pharmaceuticals Corporation. Revised May 2018. Available at: https://www. fda.gov/downloads/UCM573941.pdf. Accessed December 1, 2018.

42. Yescarta (axicabtagene ciloleucel) suspension for intravenous infusion. Kite Pharma. October 2017. Available at: https://www.fda.gov/downloads/ UCM581226.pdf. Accessed December 1, 2018.

43. May C, Rivella S, Callegari J, et al. Therapeutic haemoglobin synthesis in beta-thalassaemic mice expressing lentivirus-encoded human beta-globin. Nature. 2000;406(6791):82-86.

44. Thompson AA, Walters MC, Kwiatkowski J, et al. Gene therapy in patients with transfusion-dependent $\beta$-thalassemia. N Engl J Med. 2018;378(16):1479-93.

45. Wu C, Dunbar CE. Stem cell gene therapy: the risks of insertional mutagenesis and approaches to minimize genotoxicity. Front Med. 2011;5(4):356-71

46. Cavazzana-Calvo M, Payen E, Negre O, et al. Transfusion independence and HMGA2 activation after gene therapy of human $\beta$-thalassaemia. Nature. 2010;467(7313):318-22.

47. Biffi A, Montini E, Lorioli L, et al. Lentiviral hematopoietic stem cell gene therapy benefits metachromatic leukodystrophy. Science. 2013;341(6148):1233158.

48. Eichler F, Duncan C, Musolino PL, et al. Hematopoietic stem-cell gene therapy for cerebral adrenoleukodystrophy. N Engl J Med. 2017;377(17):1630-38.

49. Choudhury SR, Hudry E, Maguire CA, Sena-Esteves M, Breakefield XO, Grandi P. Viral vectors for therapy of neurologic diseases. Neuropharmacology. 2017:120:63-80.

50. Kessler PD, Podsakoff GM, Chen X, et al. Gene delivery to skeletal muscle results in sustained expression and systemic delivery of a therapeutic protein. Proc Natl Acad Sci USA. 1996;93(24):14082-87.

51. Xiao X, Li J, Samulski RJ. Efficient long-term gene transfer into muscle tissue of immunocompetent mice by adeno-associated virus vector. J Virol. 1996;70(11):8098-108.

52. Srivastava A. In vivo tissue-tropism of adeno-associated viral vectors. Curr Opin Virol. 2016;21:75-80.

53. Kay MA, Manno CS, Ragni MV, et al. Evidence for gene transfer and expression of factor IX in haemophilia B patients treated with an AAV vector. Nat Genet. 2000;24(3):257-61

54. Manno CS, Pierce GF, Arruda VR, et al. Successful transduction of liver in hemophilia by AAV-Factor IX and limitations imposed by the host immune response. Nat Med. 2006;12(3):342-47.

55. Kumar SR, Markusic DM, Biswas M, High KA, Herzog RW. Clinical development of gene therapy: results and lessons from recent successes. Mol Ther Methods Clin Dev. 2016;3:16034.
56. Leone P, Shera D, McPhee SW, et al. Long-term follow-up after gene therapy for canavan disease. Sci Transl Med. 2012;4(165):165ral63.

57. Wright JF. Adeno-associated viral vector manufacturing: keeping pace with accelerating clinical development. Hum Gene Ther. 2011;22(8):913-14.

58. Mingozzi F, Maus MV, Hui DJ, et al. CD8(+) T-cell responses to adenoassociated virus capsid in humans. Nat Med. 2007;13(4):419-22.

59. McCarty DM, Monahan PE, Samulski RJ. Self-complementary recombinant adeno-associated virus (scAAV) vectors promote efficient transduction independently of DNA synthesis. Gene Ther. 2001;8(16):1248-54.

60. Foust KD, Wang X, McGovern VL, et al. Rescue of the spinal muscular atrophy phenotype in a mouse model by early postnatal delivery of SMN. Nat Biotechnol. 2010;28(3):271-74.

61. Meyer K, Ferraiuolo L, Schmelzer L, et al. Improving single injection CSF delivery of AAV9-mediated gene therapy for SMA: a dose-response study in mice and nonhuman primates. Mol Ther. 2015;23(3):477-87.

62. Lopes JM. \#AAN2018 - Type 1 SMA babies treated with AVXS-101 achieving new milestones, trials show. SMA News Today. April 24, 2018. Available at: https://smanewstoday.com/2018/04/24/aan2018-type-1-sma-babies-avxs101-continue-improve-clinical-trials. Accessed November 30, 2018.

63. U.S. National Library of Medicine. ClinicalTrials.gov. Gene replacement therapy clinical trial for patients with spinal muscular atrophy type 1 (STR1VE). Available at: https://clinicaltrials.gov/ct2/show/NCT03306277. Accessed November 30, 2018.

64. U.S. National Library of Medicine. ClinicalTrials.gov. Pre-symptomatic study of intravenous AVXS-101 in spinal muscular atrophy (SMA) for patients with multiple copies of SMN2 (SPRINT). Available at: https:// clinicaltrials.gov/ct2/show/NCT03505099?term=NCT03505099\&rank=1. Accessed November 30, 2018.

65. U.S. National Library of Medicine. ClinicalTrials.gov. Study of intrathecal administration of AVXS-101 for spinal muscular atrophy (STRONG). Available at: https://clinicaltrials.gov/ct2/show/NCT03381729. Accessed November 30, 2018.

66. Lopes JM. AVXS-101 sets out to show it might be 'transformative' for all SMA types: interview with AveXis. SMA News Today. February 13, 2018. Available at: https://smanewstoday.com/2018/02/13/series-of-trials-willshow-if-avexis-gene-therapy-can-be-a-game-changer-for-sma/. Accessed November 30, 2018.

67. Kegel ML. FDA lets AveXis know the information it needs to possibly approve AVXS-101 for SMA type 1. SMA News Today. January 8, 2018. Available at: https://smanewstoday.com/2018/01/08/fda-gives-avexis-the-lowdown-onapproving-its-therapy-for-sma-type-1/. Accessed November 30, 2018.

68. U.S. Food and Drug Administration, Center for Drug Evaluation and Research. Advancing health through innovation: 2017 new drug approvals. January 2018. Available at: https://www.fda.gov/downloads/AboutFDA/ CentersOffices/OfficeofMedicalProductsandTobacco/CDER/ReportsBudgets/ UCM591976.pdf. Accessed November 30, 2018.

69. Aitken M, Kleinrock M. Orphan drugs in the United States. IQVIA Institute. October 2017. Available at: https://rarediseases.org/wp-content/ uploads/2017/10/Orphan-Drugs-in-the-United-States-Report-Web.pdf. Accessed November 30, 2018.

70. Tyler LS, Cole SW, May JR, et al; ASHP Expert Panel on Formulary Management. ASHP guidelines on the pharmacy and therapeutics committee and the formulary system. Am J Health Syst Pharm. 2008;65(13):1272-83.

71. Principles of a sound drug formulary system. In: Hawkins B, ed. Best Practices for Hospital and Health System Pharmacy: Positions and Guidance Documents of ASHP. 2006-2007 ed. Bethesda, MD: American Society of Health-System Pharmacists; 2006:110-13.

72. U.S. Food and Drug Administration. Statement from FDA Commissioner Scott Gottlieb, M.D., on administration's request for new FDA funding to promote innovation and broaden patient access through competition. February 13, 2018. Available at: https://www.fda.gov/newsevents/newsroom/ pressannouncements/ucm596554.htm. Accessed November 30, 2018. 
73. Kent A, Spink J. Will rising prices and budget constraints prevent patients from accessing novel gene therapies? Gene Ther. 2017;24(9):542-43.

74. AveXis. 10-K Annual report. February 2018. Available at: https://www. last10k.com/sec-filings/avxs/0001558370-18-001313.htm. Accessed November 30, 2018.

75. Clarke T, Berkrot B. FDA approves Gilead cancer gene therapy; price set at $\$ 373,000$. Reuters. Health News. October 18, 2017. Available at: https://www. reuters.com/article/us-gilead-sciences-fda/fda-approves-gilead-cancer-genetherapy-price-set-at-373000-idUSKBNICN35H. Accessed November 30, 2018.

76. Clarke T. Spark to charge $\$ 850,000$ per patient for blindness gene therapy. Reuters. Health News. January 3, 2018. Available at: https://www.reuters. com/article/us-spark-genetherapy/spark-to-charge-850000-per-patient-forblindness-gene-therapy-idUSKBN1ES17W. Accessed November 30, 2018.

77. Beasley D. US approves Novartis cell therapy for lymphoma. Reuters. Health News. May 1, 2018. Available at: https://www.reuters.com/article/usnovartis-pharmaceuticals/us-approves-novartis-cell-therapy-for-lymphomaidUSKBN1I24GP. Accessed November 30, 2018.

78. King NMP, Bishop CE. New treatments for serious conditions: ethical implications. Gene Ther. 2017;24(9):534-38.

79. Davey P, Brown E, Fenelon L, et al. Interventions to improve antibiotic prescribing practices for hospital inpatients. Cochrane Database Syst Rev. 2005;(4):CD003543

80. Biogen. Spinraza fact sheet. May 2018. Available at: https://www.spinraza-hcp.com/content/dam/commercial/specialty/spinraza/hcp/en_us/pdf/SPZUS-0108_SPINRAZA-Product-Fact-Sheet.pdf. Accessed December 1, 2018.

81. Heindel G, Smith J, Cruz J, Pappas A. Utilizing a drug information center for submitting reconsiderations for local coverage determinations. Am J Health Syst Pharm. 2017;74(3):106-07.
82. U.S. Centers for Medicare \& Medicaid Services. New medical services and new technologies. Available at: https://www.cms.gov/Medicare/ Medicare-Fee-for-Service-Payment/AcuteInpatientPPS/newtech.html. Accessed November 30, 2018.

83. Haataja L, Mercuri E, Regev R, et al. Optimality score for the neurologic examination of the infant at 12 and 18 months of age. J Pediatr. 1999; 135(2 pt 1):153-61.

84. Romeo DM, Ricci D, Brogna C, Mercuri E. Use of the Hammersmith Infant Neurological Examination in infants with cerebral palsy: a critical review of the literature. Dev Med Child Neurol. 2016;58(3):240-45.

85. Mercuri E, Finkel R, Montes J, et al. Patterns of disease progression in type 2 and 3 SMA: implications for clinical trials. Neuromuscul Disord. 2016;26(2):123-31.

86. Glanzman AM, O'Hagen JM, McDermott MP, et al; the Pediatric Neuromuscular Clinical Research Network for Spinal Muscular Atrophy (PNCR), and the Muscle Study Group (MSG). Validation of the Expanded Hammersmith Functional Motor Scale in spinal muscular atrophy type II and III. J Child Neurol. 2011;26(12):1499-507.

87. Glanzman AM, Mazzone E, Main M, et al. The Children's Hospital of Philadelphia Infant Test of Neuromuscular Disorders (CHOP INTEND): test development and reliability. Neuromuscul Disord. 2010;20(3):155-61.

88. Glanzman AM, McDermott MP, Montes J. Validation of the Children's Hospital of Philadelphia Infant Test of Neuromuscular Disorders (CHOP INTEND). Pediatr Phys Ther. 2011;23(4):322-26.

89. Bérard C, Payan C, Hodgkinson I, Fermanian J; MFM Collaborative Study Group. A motor function measure for neuromuscular diseases. Construction and validation study. Neuromuscul Disord. 2005;15(7):463-70. 


\section{Posttest Questions}

1. What was the median time of death in the NeuroNEXT natural history study of patients with type 1 spinal muscular atrophy (SMA) ages $<6$ months?
a. 18 months
b. 12 months
c. 8 months
d. 4 months

2. Which of the following is NOT a characteristic of the adeno-associated viral (AAV) vectors currently used in gene therapy protocols?
a. They can carry up to $5 \mathrm{~kb}$ of DNA.
b. They typically integrate into the host genome.
c. They form stable episomes in host cells.
d. They were engineered from a nonpathogenic parvovirus.

3. Which is the underlying genetic defect in $\sim 95 \%$ of cases of SMA?
a. Point mutations in the SMN2 gene
b. Point mutations in the SMN1 gene
c. Mutations in the promoter that regulates SMN2 gene expression
d. Homozygous deletion in SMN1

4. At the time of publication of the AVXS-101 phase 1 clinical trial, how many of the 12 children who received the higher dose of gene therapy had rolled over (compared to no children achieving this motor milestone in natural history studies)?
a. 12
b. 9
c. 6
d. 3

5. Which of the following is NOT a universal strategy directing use of a medication identified for formulary inclusion within a health system?
a. Adherence to specific-use criteria
b. Development of clinical practice guidelines
c. Requirement for approval by a medical director, division chair, or other clinical leader
d. Placing cost of treatment as most important in the hierarchy of considerations 


\section{Supplement}

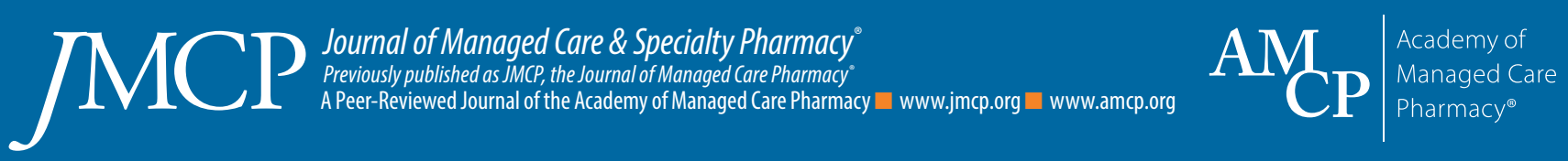

